\title{
A Novel Dynamic Wavelength Cross-connect Based on Mach-Zehnder Interferometer Optical ad/drop Multiplexer and Optical Space \\ Switch
}

\author{
Xueyan, Zheng; Liu, Fenghai
}

Published in:

Proceedings of CLEO'99 - Pacific rim

Link to article, DOI:

10.1109/CLEOPR.1999.817831

Publication date:

1999

Document Version

Publisher's PDF, also known as Version of record

Link back to DTU Orbit

Citation (APA):

Xueyan, Z., \& Liu, F. (1999). A Novel Dynamic Wavelength Cross-connect Based on Mach-Zehnder Interferometer Optical ad/drop Multiplexer and Optical Space Switch. In Proceedings of CLEO'99 - Pacific rim (Vol. 3). IEEE. https://doi.org/10.1109/CLEOPR.1999.817831

\section{General rights}

Copyright and moral rights for the publications made accessible in the public portal are retained by the authors and/or other copyright owners and it is a condition of accessing publications that users recognise and abide by the legal requirements associated with these rights.

- Users may download and print one copy of any publication from the public portal for the purpose of private study or research.

- You may not further distribute the material or use it for any profit-making activity or commercial gain

- You may freely distribute the URL identifying the publication in the public portal 


\title{
A Novel Dynamic Wavelength Cross-connect Based on Mach-Zehnder Interferometer Optical add/drop Multiplexer and Optical Space Switch
}

\author{
Xueyan Zheng and Fenghai Liu \\ Research Centre COM, Technical University of Denmark, \\ Building 349, DK-2800, Lyngby, Denmark, \\ Phone: (45)-4525-3777, Fax: (45)-4593-6581, E-mail: zx@com.dtu.dk
}

\section{Introduction:}

Wavelength Cross-connect (WXC) is one of the key components in future all-optical wavelength division multiplexing (WDM) networks [1]. WXC reduces congestion in cross-connect nodes, enhances the survivability of WDM networks, makes WDM networks be reconfigured and expanded easily. Recently, a dynamic WXC based on fiber grating and optical space switch is proposed [2][3]. However, in this structure, the differential insert loss (DIL) for different paths in the WXC limits it to be used in WDM networks.

In this paper, a novel dynamic WXC structure employing optical space witch (OSW) and Bragg grating based Mach-Zehnder interferometer (MZI) optical add/drop Multiplexer (OADM) is proposed. In this structure, the DIL of different paths will not limit the scalability and cascading of the WXC in WDM networks with large number of wavelengths. Furthermore, the exchanging units used in the dynamic WXC are reduced by one half, compared to Ref. [3]. Since no circulator is needed in this structure, the WXC can be integrated. In experiment, the path with maximum number of OADMs in a dynamic $2 \times 2 \mathrm{WXC}$ capable of exchanging five wavelengths is tested and shows high performance.

\section{Structure of the WXC:}

Using a cascaded MZI-OADM with different central wavelength (meeting the ITU WDM standardisation), a static $2 \times 2 \mathrm{WXC}$ is realized, as shown in Fig. 1. In the static $2 \times 2 \mathrm{WXC}$, each input wavelength will be exchanged by the OADM with the same central wavelength, and pass all other OADMs. Since each wavelength is exchanged once at most, the maximum DIL of all wavelengths into the $2 \times 2$ static WXC is the DIL between the dropped and the passed wavelengths in one OADM, no matter how many OADMs are cascaded. This remarkable feature makes the structure can be expanded to large dimensions. For presently used OADMs, the DII between intra-band and out-band wavelength is less than $0.2 \mathrm{~dB}$.

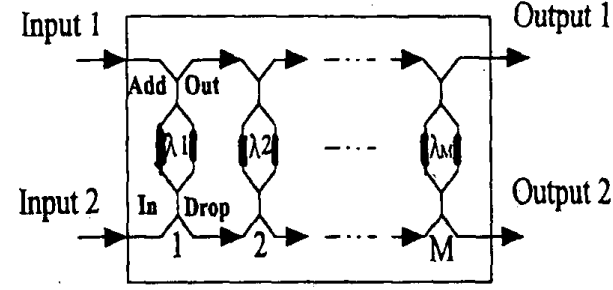

Fig. 1 Static $2 \times 2 \mathrm{WXC}$.

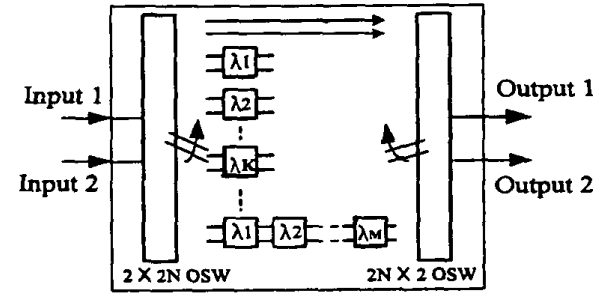

Fig. 2 Dynamic $2 \times 2$ WXC.

Using $\mathrm{N}$ pieces of $2 \times 2$ static WXCs with different stages and two $2 \times 2 \mathrm{~N}$ OSW, a $2 \times 2$ dynamic WXC is realized, as shown in Fig. 2. Switching the OSW to proper position, any of wavelengths in the two input fibers can be exchanged. Assuming $\mathrm{K}$ wavelengths in each fiber, if all the $\mathrm{K}$ wavelengths need to be exchanged, it can be realized by switching the two fibres. The two direct paths in Fig.2 are designed for this situation. If K-1 wavelengths need to be exchanged, and assuming $\lambda_{1}$ need not to be exchanged, the left OSW will switch the two input fiber to the input port of the $2 \times 2$ static WXC unit which exchanges $\lambda_{1}$. At the output of the $2 \times 2$ static WXC unit, the right OSW will switch the output signal to finish the requirement. So, only one OADM is needed for exchanging K-1 wavelengths, two OADMs are needed for exchanging K-2 wavelengths. In the $2 \times 2$ WXC dynamic WXC, if $K$ is odd, the maximum number of cascaded OADMs in the largest $2 \times 2$ static WXC units is $(\mathrm{K}-1) / 2$, if $\mathrm{K}$ is even, the maximum number is $\mathrm{K} / 2$. The number of $2 \times 2$ static WXC units needed is:

$$
N=\left(C_{K}^{0}+C_{K}^{1}+C_{K}^{2}+\ldots \ldots C_{K}^{K}\right) / 2
$$

The number of the exchanging units needed in the $2 \times 2 \mathrm{WXC}$ dynamic $\mathrm{WXC}$ is reduced by one half compared to Ref. [3]. Using less exchanging units is good for reducing the crosstalk in the WXC. Because no circulator is used, the device can be integrated. 
As mentioned above, the DIL of the different wavelengths in each $2 \times 2$ static WXC unit is equal, corresponding attenuators can be added after each $2 \times 2$ static WXC unit to balance the loss of different paths in the $2 \times 2$ dynamic WXC. Based on $2 \times 2$ dynamic WXC, a rearrangeably nonblocking $\mathrm{K} \times \mathrm{K}$ WXC can be formed using classical method [4]. Assuming the DIL between the dropped and the passed wavelengths in an OADM is $0.2 \mathrm{~dB}$, for a $128 \times 128$ dynamic WXC based on this scheme, the maximum DIL in all paths is only $2.6 \mathrm{~dB}$. So, the DIL will not limit the scalability and the cascading of this kind of WXC in WDM networks with large number of wavelengths.

\section{Experimental setup and results:}

To investigate the feasibility of this kind of dynamic WXC, a path with the maximum number of OADMs in a $2 \times 2$ dynamic WXC capable of exchanging five wavelengths is tested, by using two cascaded fiber grating based MZI-OADMs. Because the OSW does not deteriorate the WXC (the crosstalk of the commercial OSW can reach $-75 \mathrm{~dB}$ ), the OSW is replaced by a fixed connection. Fig. 3 shows the experiment setup. Three DFB lasers with wavelengths $1552.4 \mathrm{~nm}\left(\lambda_{1}\right), 1555.6 \mathrm{~nm}\left(\lambda_{2}\right)$ and $1558.8 \mathrm{~nm}\left(\lambda_{3}\right)$ are used. After multiplexed and then amplified by EDFA1, the three channels are modulated together by a LN modulator with a $2^{11}-1$ NRZ pseudorandom bit sequence at $10 \mathrm{~Gb} / \mathrm{s}$. Then, it is amplified again by EDFA2, and divided into two paths by the coupler. One of them is delayed by $1 \mathrm{~km}$ dispersion-shifted fibre. The two paths of WDM signal are injected into the WXC. In the WXC, $\lambda_{3}$ is exchanged by the OADM with central wavelength $1558.8 \mathrm{~nm}$ and passes through the OADM with central wavelength $1555.6 \mathrm{~nm}$. $\lambda_{2}$ is exchanged by the OADM with central wavelength $1555.6 \mathrm{~nm}$ and pass through the OADM with central wavelength $1558.8 \mathrm{~nm}$. $\lambda_{1}$ passes through the two OADMs. After demultiplexed, the bit error rate (BER) of the three channels is detected. Fig.4 shows the BER of the three channels. $\lambda_{1}$ and $\lambda_{3}$ show the negligible power penalty $0.2 \mathrm{~dB}, \lambda_{2}$ shows $0.3 \mathrm{~dB}$ power penalty at BER of $10^{-9}$. The system operation and performance confirm the feasibility of the novel structure WXC.

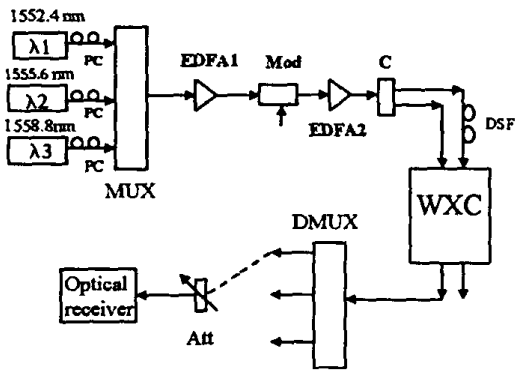

Fig. 3 Experimental setup. C: Coupler, Att: Attenuator, PC. Polarisation Controller, DSF: Dispersion Shifted Fiber.

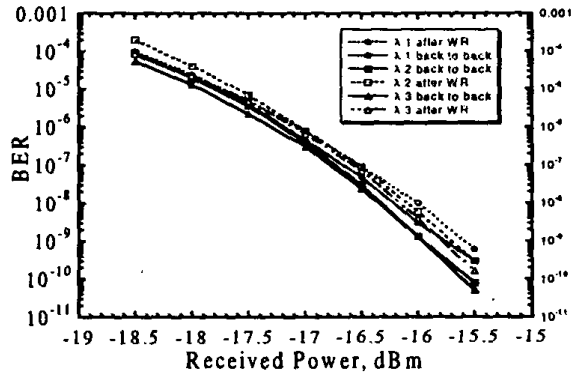

Fig. 4 BER performance of the three channels for back-to-back and after the WXC at 10Gb/s.

Besides scalability of the WXC and using less switch units, there are other important features for the WXC with potentially low crosstalk and the ability to be integrated.

\section{Conclusion:}

We have proposed a novel dynamic WXC based on MZI-OADM. The advantages of this dynamic WXC are very low DIL, using less exchanging units than reported structure, and the ability to be integrated. In experiment, the three channels from the path with maximum OADMs in a $2 \times 2$ dynamic WXC capable of exchanging five wavelengths show negligible power penalty at BER of $10^{-9}$. The above advantages make this kind of dynamic WXC very promising for the future WDM networks.

Reference:

[1] W. D. Zhong, J. P. R. Lacey, R. S. Tucker, "Wavelength Cross-connect for Optical Transport Networks", IEEE. J. Lightwave Technol, vol. 14, 1996, pp 1613-1620.

[2] S. K. Liaw, K. P. Ho and S. Chi, " Multichannel add/drop and cross-connect using fibre Bragg grating and optical switches, " Electronics Lett, vol. 34, 1998, pp 1601-1603.

[3] Y. K. Chen and C. C. Lee, "Fibre Bragg Grating-Based Large Nonblocking Wavelength Cross-connects," J. Lightwave Technol, vol. 16, 1998, pp 1746-1756.

[4] Joseph Y. Hui, Switching and Traffic Theory for Integrated Broadband Networks. Boston: Kluwer Academic, 1994. 